J. Lake Sci.(湖泊科学), 2009, 21(5): 623-630

http://www.jlakes.org. E-mail: jlakes@niglas.ac.cn

(C2009 by Journal of Lake Sciences

\title{
湖泊表层沉积物可溶性有机氮含量及分布特性
}

\author{
林素梅 ${ }^{1,2}$, 王圣瑞 ${ }^{2}$, 金相灿 ${ }^{2}$, 何星存 ${ }^{3}$ \\ (1: 广西师范大学化学化工学院, 桂林 541004) \\ (2: 中国环境科学研究院湖泊环境创新基地，国家环境保护湖泊污染控制重点实验室，北京 100012) \\ (3: 广西师范大学环境与资源学院, 桂林 541004)
}

摘 要: 选择鄱阳湖、洞庭湖等 6 个湖泊的 15 个表层沉积物样品, 用 $1 \mathrm{~mol} / \mathrm{L} \mathrm{KCl}$ 溶液提取沉积物中的可溶性有机氮( $\mathrm{SON})$, 并 研究了 SON 的含量、分布状况及特性. 结果表明, 所研究的沉积物 SON 含量变异较大, 在 $17.18-292.31 \mathrm{mg} / \mathrm{kg}$ 之间波动, 平均 为 $134.45 \mathrm{mg} / \mathrm{kg}$, 占可溶性总氮(TSN)的 $51.86 \%$, 沉积物总氮的 7.14\%. 污染程度重的沉积物中 SON 含量均较污染程度轻的高, 且 SON 含量与 TN、TSN 含量呈正相关, 即与沉积物氮污染程度呈正相关. 分布状况则与湖泊污染程度、人类活动干扰强度等 紧密相关. 所研究表层湖泊沉积物中游离氨基酸(FAA)含量处于 4.69-42.04mg/kg 间, 平均为 $23.27 \mathrm{mg} / \mathrm{kg}$, 占 SON 的 $18.80 \%, T N$ 的 1.24\%. FAA 与 SON 含量呈显著正相关, 在沉积物中的平均含量及在 SON 中的比例均较土壤中高, 说明湖泊沉积物 SON 有 较大的易分解组分. SON 与沉积物可溶性无机氮、有机质、CEC 等显著相关. 因此, SON 是湖泊沉积物氮的重要组成部分, 对湖 泊富营养化具有重要的影响, 特别是对污染严重的沉积物而言, 更应重视其 SON 在湖泊氮循环及富营养化中的作用.

关键词: 湖泊表层沉积物; 可溶性有机氮; 含量; 游离氨基酸; 鄱阳湖; 洞庭湖

\section{Contents and distribution characteristics of soluble organic nitrogen in surface sediments of lakes}

LIN Sumei ${ }^{1,2}$, WANG Shengrui ${ }^{2}$, JIN Xiangcan ${ }^{2}$ \& HE Xingcun ${ }^{3}$

(1: College of Chemistry and Chemical Engineering, Guangxi Normal University, Guilin 541004, P.R.China)

(2: State Environmental Protection Key Laboratory of Lake Pollution Control, Research Center of Lake Environment, Chinese Research Academy of Environmental Science, Beijing 100012, P.R.China)

(3: College of Environmental Science and Resource, Guangxi Normal University, Guilin 541004, P.R.China)

Abstract: The contents and distribution characteristics of soluble organic nitrogen (SON) extracted with $1 \mathrm{~mol} / \mathrm{L} \mathrm{KCl}$ from the sediments of six typical lakes including Lake Poyang, Lake Dongting in Hunan and Jiangxi Provinces were studied. The results indicated that the SON contents varied greatly from $17.18 \mathrm{mg} / \mathrm{kg}$ to $292.31 \mathrm{mg} / \mathrm{kg}$ (mean content, $134.45 \mathrm{mg} / \mathrm{kg}$ ), comprising $51.86 \%$ of total soluble nitrogen (TSN) and 7.14\% of total nitrogen (TN) in six lakes. The SON contents were significantly correlated with their contents of TN and TSN, and SON were higher in the heavily polluted sediments than the light polluted ones. Their distributions of SON were closely related to their lake pollution levels. The contents of free amino acid in the sediments were also studied, and they varied from 4.69 to $42.04 \mathrm{mg} / \mathrm{kg}$, comprising $18.80 \%$ of SON, and $1.24 \%$ of TN, and were significantly correlated with their SON contents. The mean content of FAA was $23.27 \mathrm{mg} / \mathrm{kg}$, higher than those in soils in the same region. It indicated that there was more bioavailable SON from lake sediment than those from soil. The contents of SON in the sediments were also correlated with inorganic nitrogen, OM and CEC and so on. As one of the most important nitrogen compositions in lake sediments, SON should be paid more attention to the nitrogen cycling and entrophication control in lakes.

* 国家自然科学基金项目(40873079)、科技部基础性工作专项重点项目“中国湖泊水质、水量和生物资源调查”(2006FY110600) 和中央级公益性科研院所基本科研业务专项项目(2007KYYW27)联合资助. 2009-01-04 收稿; 2009-02-19 收修改稿. 林 素梅, 女, 1982 年生, 硕士研究生; E-mail: linsumei2010@163.com. 

Keywords: Surface sediment of lake; soluble organic nitrogen; contents; free amino acid; Lake Poyang; Lake Dongting

目前, 关于可溶性有机氮(Soluble Organic Nitrogen, SON)的研究主要集中在土壤方面. 可溶性有机 氮定义为土壤中能够被水、盐溶液或用电超滤法(EUF)提取出来的有机态氮 ${ }^{[1]}$, 它是土壤中主要的可溶性 氮库, 是微生物和植物的潜在可利用氮源 ${ }^{[2]}$. 一些低分子量的SON组分, 如游离氨基酸 (Free Amino Acid, FAA)等, 是微生物的重要来源, 能被植物直接吸收 ${ }^{[3-4]}$. 有机氮是沉积物中最主要的氮素组分, 因而可溶 性的有机态氮必定是含量较大的有机氮库. 目前对湖泊溶解有机氮的研究主要集中在湖泊水体及沉积物 孔隙水方面 ${ }^{[5-6]}$, 对利用水或盐溶液提取的有机态氮, 即 $\mathrm{SON}$ 的研究尚不多见. 土壤中的 SON能被直接释 放出来 ${ }^{[7]}$, 且在特殊情况下, 藻类在吸收 $N$ 源时能直接吸收或更倾向于吸收溶解有机氮而不是溶解无机 氮 ${ }^{[8]}$. 前人研究表明, 陆地生态系统土壤中的 SON有较强的移动性, 易被淋失而进人湖泊, 对湖泊藻类氮 素供应甚至湖泊富养化产生显著影响 ${ }^{[9-10]}$, 且有研究认为沉积物释放是湖泊水体溶解有机氮的重要来 源 ${ }^{[5]}$. 因此, 研究SON在湖泊沉积物中的含量及其分布特性对理解湖泊富营养化过程具有重要意义.

SON的含量较复杂, 其中以低分子量物质为主的SON主要含有尿素、游离氨基酸 ${ }^{[4]}$ 等. 由于FAA可以 被植物吸收, 且会较快为土壤微生物所降解, 因而是土壤SON中较为活跃的组分之一 ${ }^{[11]}$. 沉积物中FAA 的研究较多 ${ }^{[2]}$, 但其与SON的含量关系研究较少.

本研究选取位于湖南、江西两省的 6 个湖泊, 研究其表层沉积物中 SON 和游离氨基酸的含量、分布特征, SON 特性等, 为进一步研究 SON 在湖泊系统氮循环中的作用及其对湖泊富营养化的影响等提供依据.

\section{1 材料与方法}

\section{1 研究区概况}

本研究涉及 6 个湖泊(图1). 其中鄱阳湖是中国最大的淡水湖, 湖泊面积 $2933 \mathrm{~km}^{2}$, 平均水深 $5.1 \mathrm{~m}$, 水 位变幅巨大, 属吞吐性湖泊, 其水质在五大淡水湖中较好 ${ }^{[13]}, 2007$ 年水质总体为 IV 类, 处于中营养状态. 军山湖位于江西省进贤县, 是鄱阳湖的子湖泊, 湖泊面积 $192.5 \mathrm{~km}^{2}$, 平均水深 $4 \mathrm{~m}$, 是重要的养殖湖泊, 渔 业历史悠久, 湖泊周围乡村众多, 人口密集, 耕地面积大, 一遇暴雨, 即将周围村庄和农田中的肥水冲人 湖中, 污染较为严重 ${ }^{[14]}$.
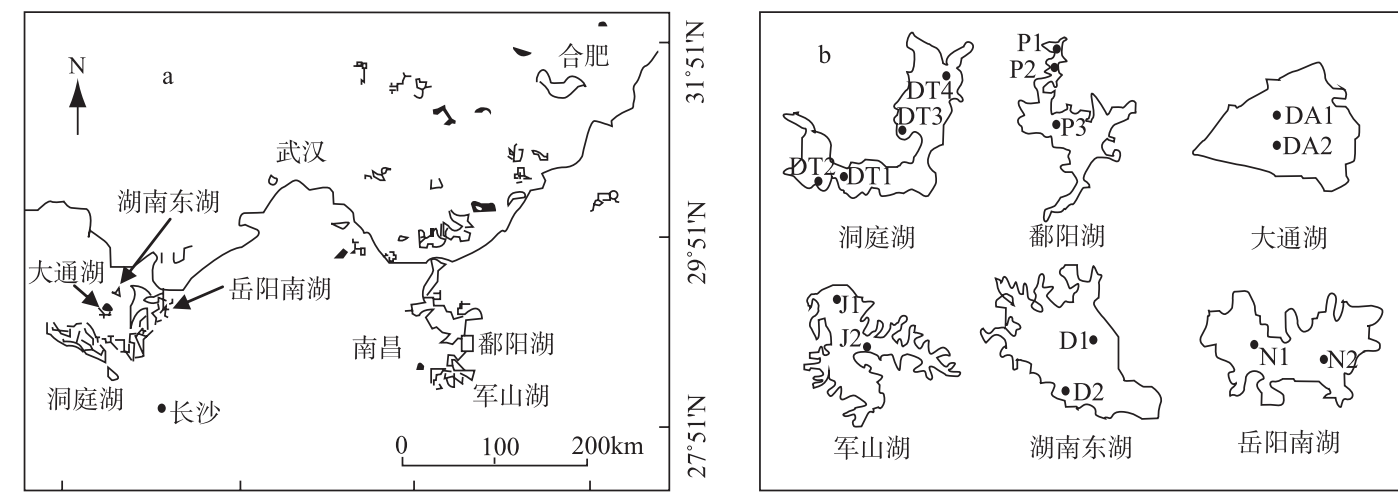

$111^{\circ} 38^{\prime} \mathrm{E} \quad 113^{\circ} 38^{\prime} \mathrm{E}$

$115^{\circ} 38^{\prime} \mathrm{E}$

$117^{\circ} 38^{\prime} \mathrm{E}$

图1 湖泊(a)及采样点位置(b)

Fig.1 Location of the lakes(a) and sampling sites(b)

洞庭湖是我国第二大淡水湖, 是长江中游一个重要集水蓄洪湖泊, 湖泊面积 $2432.5 \mathrm{~km}^{2}$, 平均水深 $6.39 \mathrm{~m}$, 全湖水质较好, 污染程度与鄱阳湖相似, 但存在潜在变劣趋势 ${ }^{[15]}$. 湖南东湖位于洞庭湖区华容县, 湖泊面积 $23.2 \mathrm{~km}^{2}$, 平均水深 $3.5 \mathrm{~m}$, 湖内天然饵料丰富, 是华容县最大的养殖场, 受养殖影响, 污染也较 严重, 水质达中-富营养状态 ${ }^{[16]}$. 大通湖位于湖南省益阳市, 湖泊面积 $114.2 \mathrm{~km}^{2}$, 平均水深 $2.89 \mathrm{~m}$, 岸线平 直, 湖底平坦, 淤泥多, 水质状况为中-富营养化状态 ${ }^{[17]}$. 岳阳南湖位于岳阳市市郊, 湖泊面积 $12 \mathrm{~km}^{2}$, 平 
均水深 $3 \mathrm{~m}$, 水环境呈现富营养化特征. 由于多年的化肥养鱼, 大通湖与岳阳南湖已由 20 世纪 70 年代初的 草型湖转变为藻型湖, 水生态系统严重退化 ${ }^{[18]}$.

\section{2 样品采集与分析}

1.2.1 样品采集及分析于 2007 年 11 月至 12 月在湖南省的洞庭湖、大通湖、湖南东湖、岳阳南湖, 江西 省的鄱阳湖、军山湖共布设 15 个采样点(图 1), 现场用柱状采样器采集表层 $10 \mathrm{~cm}$ 沉积物, 混合均匀后置于 封口塑料袋中, 在冰盒中存放, 带回实验室. 样品经冷冻干燥机干燥后, 研磨过 100 目笁, 装人自封袋置于 干燥器内备用. 经浓 $\mathrm{H}_{2} \mathrm{SO}_{4}-\mathrm{CuSO}_{4}-\mathrm{Se}$ 催化消煮后, 用 KDY-9820 型凯氏定氮仪测定沉积物总氮含量, 经典 重铬酸钾法 ${ }^{[19]}$ 测定有机质含量, SMT 法 ${ }^{[20]}$ 测定总磷含量, EDTA-铵盐快速法 ${ }^{[21]}$ 测定阳离子代换量 (CEC).

1.2.2 可溶性有机氮的测定方法 采用 $1 \mathrm{~mol} / \mathrm{L} \mathrm{KCl}$ 溶液浸提沉积物样品(水:土 $=10: 1$ ), 在室温下恒温振荡 $1 \mathrm{~h}(200 \mathrm{r} / \mathrm{min})$, 然后在 $5000 \mathrm{r} / \mathrm{min}$ 条件下离心 $10 \mathrm{~min}$, 取上清液过 $0.45 \mu \mathrm{m}$ 滤膜后, 用紫外吸收法测定滤液 的 $\mathrm{NO}_{3}{ }^{-}-\mathrm{N}$ 含量 ${ }^{[22]}$, 纳氏试剂比色法测定提取液中 $\mathrm{NH}_{4}{ }^{+}-\mathrm{N}$ 含量, 过硫酸钾氧化法测定可溶性总氮含量 (TSN). 可溶性总氮与可溶性无机氮 $\left(\mathrm{NH}_{4}{ }^{+}-\mathrm{N} 、 \mathrm{NO}_{3}{ }^{-}-\mathrm{N}\right.$ 之和)的含量之差即为 $\mathrm{SON}$ 含量.

1.2.3 游离氨基酸的测定方法称取过 100 目沉积物样品 $4 \mathrm{~g}$ 于离心管中, 加人 $20 \mathrm{ml} 1 \mathrm{~mol} / \mathrm{L} \mathrm{KCl}$ 提取液后 恒温振荡 $1 \mathrm{~h}, 5000 \mathrm{r} / \mathrm{min}$ 离心 $15 \mathrm{~min}$. 上清液过 $0.45 \mu \mathrm{m}$ 滤膜后, 取 $2 \mathrm{ml}$ 滤液于 $10 \mathrm{ml}$ 刻度试管中, 加人 $1.25 \mathrm{ml}$ 狮三酮混合指示剂, $100^{\circ} \mathrm{C}$ 水浴加热 $25 \mathrm{~min}$, 冷却后加人 $4.5 \mathrm{ml} 10 \%$ 乙醇于 $570 \mathrm{~nm}$ 处测定吸光度值 ${ }^{[11]}$. 配制了一系列浓度梯度的甘氨酸标准溶液, 与沉积物样品一起测定, 观察甘氨酸浓度与吸光度间的决定 系数, 结果显示二者的决定系数大于 0.999 .

\section{2 结果与分析}

\section{1 沉积物营养状况}

为分析和区分沉积物的营养程度, 对各湖泊沉积物进行了营养评价 ${ }^{[23]}$. 评价方法为有机指数法和有 机氮法, 前者通常用作衡量水域沉积物的环境状况, 后者是常用来衡量湖泊表层沉积物是否遭受氮污染 的重要指标. 有机氮和有机指数法的评价结果相同(表1). 沉积物污染程度的顺序为岳阳南湖 $>$ 大通湖 $>$ 湖

表1 沉积物营养状况评价结果

Tab.1 Results of organic nitrogen and organic index in sediments

\begin{tabular}{|c|c|c|c|c|c|}
\hline 样品所在湖泊 & 沉积物编号 & 总氮 $(\%)$ & 有机质 $(\%)$ & 有机氮 $(\%)$ & 有机指数 \\
\hline \multirow[t]{5}{*}{ 洞庭湖 } & DT1 & 0.105 & 2.00 & 0.100 & 0.116 \\
\hline & DT2 & 0.064 & 1.16 & 0.061 & 0.041 \\
\hline & DT3 & 0.124 & 1.60 & 0.118 & 0.109 \\
\hline & DT4 & 0.104 & 2.09 & 0.099 & 0.120 \\
\hline & 平均 & 0.099 & 1.71 & $0.096(\mathrm{III})$ & 0.097 ( II ) \\
\hline \multirow[t]{4}{*}{ 鄱阳湖 } & $\mathrm{P} 1$ & 0.114 & 1.79 & 0.108 & 0.112 \\
\hline & $\mathrm{P} 2$ & 0.102 & 1.94 & 0.097 & 0.109 \\
\hline & P3 & 0.111 & 1.73 & 0.105 & 0.106 \\
\hline & 平均 & 0.109 & 1.82 & $0.103(\mathrm{III})$ & 0.109 (II) \\
\hline \multirow[t]{3}{*}{ 大通湖 } & DA1 & 0.241 & 3.95 & 0.229 & 0.525 \\
\hline & DA2 & 0.224 & 3.45 & 0.213 & 0.426 \\
\hline & 平均 & 0.233 & 3.70 & $0.221(\mathrm{IV})$ & 0.476 (III) \\
\hline \multirow[t]{3}{*}{ 军山湖 } & $\mathrm{J} 1$ & 0.190 & 2.64 & 0.181 & 0.276 \\
\hline & $\mathrm{J} 2$ & 0.212 & 2.58 & 0.201 & 0.301 \\
\hline & 平均 & 0.201 & 2.61 & $0.191(\mathrm{IV})$ & 0.289 (III) \\
\hline \multirow[t]{3}{*}{ 湖南东湖 } & D1 & 0.269 & 3.35 & 0.256 & 0.497 \\
\hline & $\mathrm{D} 2$ & 0.160 & 2.00 & 0.152 & 0.176 \\
\hline & 平均 & 0.215 & 2.68 & $0.204(\mathrm{IV})$ & 0.337 (III) \\
\hline \multirow[t]{3}{*}{ 岳阳南湖 } & $\mathrm{N} 1$ & 0.285 & 3.51 & 0.271 & 0.551 \\
\hline & $\mathrm{N} 2$ & 0.318 & 3.70 & 0.302 & 0.648 \\
\hline & 平均 & 0.302 & 3.61 & $0.287(\mathrm{IV})$ & $0.600(\mathrm{IV})$ \\
\hline
\end{tabular}


南东湖 $>$ 军山湖 $>$ 鄱阳湖 $>$ 洞庭湖. 其中岳阳南湖、大通湖、湖南东湖和军山湖有机氮大于 $0.133 \%$, 属于 标准IV, 有机氮污染严重; 岳阳南湖有机指数大于 0.5 , 有机污染严重; 洞庭湖、鄱阳湖有机氮和有机指 数分别属于标准III和 II, 属于尚清洁和较清洁范畴. 由此可见, 各个湖泊处于不同的污染程度, 鄱阳湖和 洞庭湖污染相对较轻, 其它 4 个湖泊的沉积物氮污染相对严重.

\section{2 沉积物可溶性有机氮含量及分布特征}

本研究条件下, 6 个湖泊 15 个沉积物样品SON含量变异较大(图2), 含量处在 $17.18-292.31 \mathrm{mg} / \mathrm{kg}$ 之间, 平均值为 $134.45 \mathrm{mg} / \mathrm{kg}$. SON 占可溶性总氮 $(\mathrm{TSN})$ 的 $18.09 \%-75.72 \%$, 平均为 $51.86 \%$, 占总氮比例为 $2.12 \%-14.68 \%$, 平均为 $7.14 \%$.

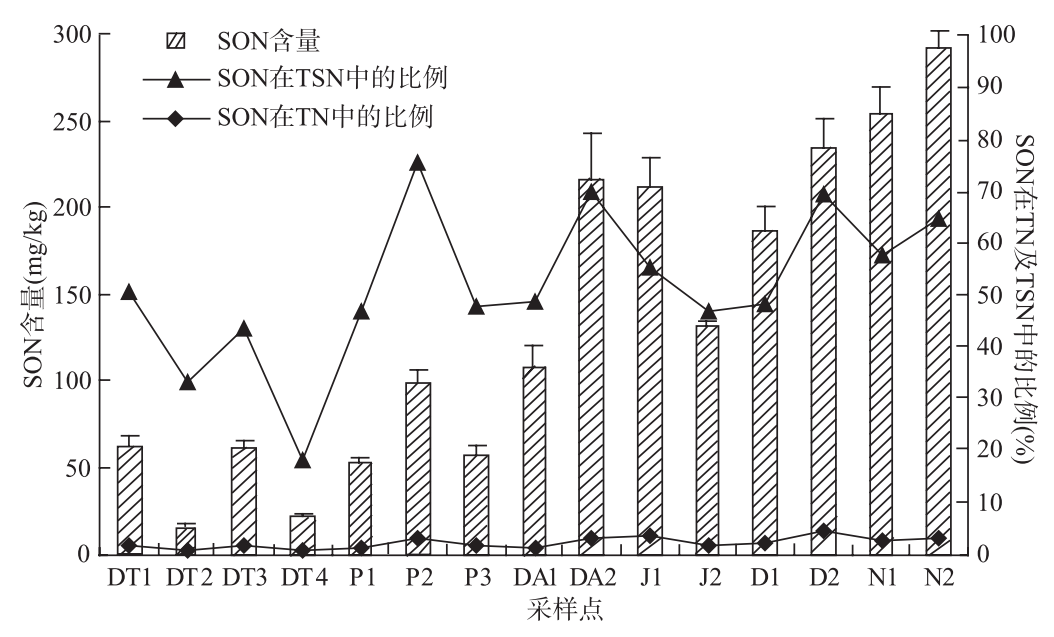

图2 湖泊沉积物中的SON含量及其在TSN、TN中的比例

Fig. 2 Contents of SON and its ratio to TSN, TN in lake sediments

污染严重的大通湖、岳阳南湖、湖南东湖和军山湖沉积物 SON含量处于 $108.90-292.31 \mathrm{mg} / \mathrm{kg}$ 之间, 污染 程度轻的洞庭湖和鄱阳湖处于 $17.18-100.39 \mathrm{mg} / \mathrm{kg}$ 之间. 总体而言, 污染严重的湖泊沉积物 SON含量均较污 染程度轻的高, 其平均值是污染程度轻湖泊的 3.8 倍. 污染程度轻的湖泊沉积物 SON占总氮的百分比为 $5.09 \%$, 污染程度重的为 $8.92 \%$, 占TSN的平均百分比分别为 $40.52 \%$ 和 $57.69 \%$, 即污染严重的沉积物中 SON 库更大. SON与沉积物总氮、可溶性总氮间显著正相关(图3), 即SON随沉积物氮污染程度的升高而增大.
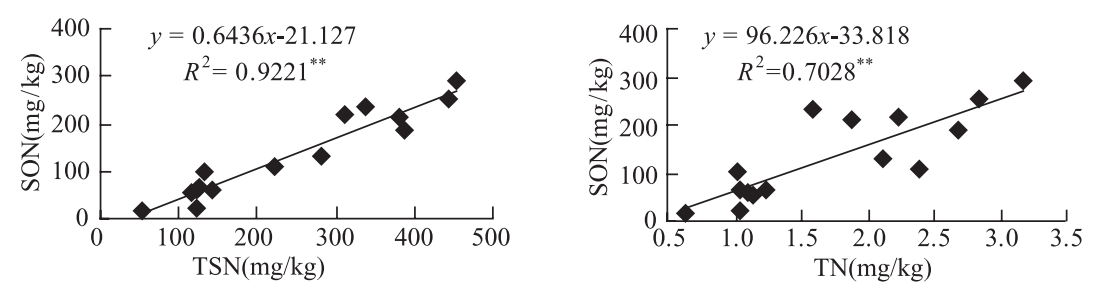

图 $3 \mathrm{SON}$ 与沉积物总氮及可溶性总氮之间的相关关系(**表示相关性达 0.01 极显著水平)

Fig. 3 Correlations between SON and TN, TSN in lake sediments

各湖泊SON平均含量由大到小的顺序为岳阳南湖 $>$ 湖南东湖 $>$ 军山湖 $>$ 大通湖 $>$ 鄱阳湖 $>$ 洞庭湖. 洞庭湖、大通湖、岳阳南湖、湖南东湖、鄱阳湖和军山湖沉积物的SON平均含量分别为 $41.25 、 163.23$ 、 $273.30 、 211.22 、 70.72$ 和 $172.04 \mathrm{mg} / \mathrm{kg}$; 占 TSN的平均百分比为 $36.48 \% 、 59.39 \% 、 61.07 \% 、 58.91 \% 、 56.84 \%$ 和 $51.37 \%$ ；占沉积物总氮的平均百分比为 $3.97 \% 、 7.12 \% 、 9.06 \% 、 10.83 \% 、 6.59 \%$ 和 $8.69 \%$. 


\section{3 沉积物中游离氨基酸的含量}

研究表明, 游离氨基酸能较快地被微生物降解, 还能被植物直接吸收, 因而是许多植物和土壤微生 物的重要可利用氮源 ${ }^{[3-4]}$. 虽然FAA在SON中所占比例不大, 但却是对微生物和浮游植物有重要影响且能 快速循环的基本有机组分 ${ }^{[24]}$. 为此, 我们研究了不同湖泊表层沉积物中的FAA含量情况, 试图探索湖泊 沉积物中FAA的含量状况及其与SON的关系, 以更好地揭示沉积物SON的特征.

FAA的含量分布也存在较大差异, 含量处于 $4.69-42.04 \mathrm{mg} / \mathrm{kg}$ 之间, 平均为 $23.27 \mathrm{mg} / \mathrm{kg}$, 平均占 $S O N$ 的 $18.80 \%$, TSN的 $9.32 \%$, TN的 $1.24 \%$. 不同湖泊沉积物FAA含量的大小顺序为军山湖 $>$ 岳阳南湖 $>$ 湖南 东湖 $>$ 大通湖 $>$ 鄱阳湖 $>$ 洞庭湖. 污染程度轻的 2 个湖泊FAA含量差异明显, 在 $4.69-18.90 \mathrm{mg} / \mathrm{kg}$ 之间波 动, 污染严重的 4 个湖泊FAA含量在 $27.39-42.04 \mathrm{mg} / \mathrm{kg}$ 之间, 变异相对较小(图4). 总体而言, 污染严重的 湖泊沉积物FAA含量均较污染程度轻的高.

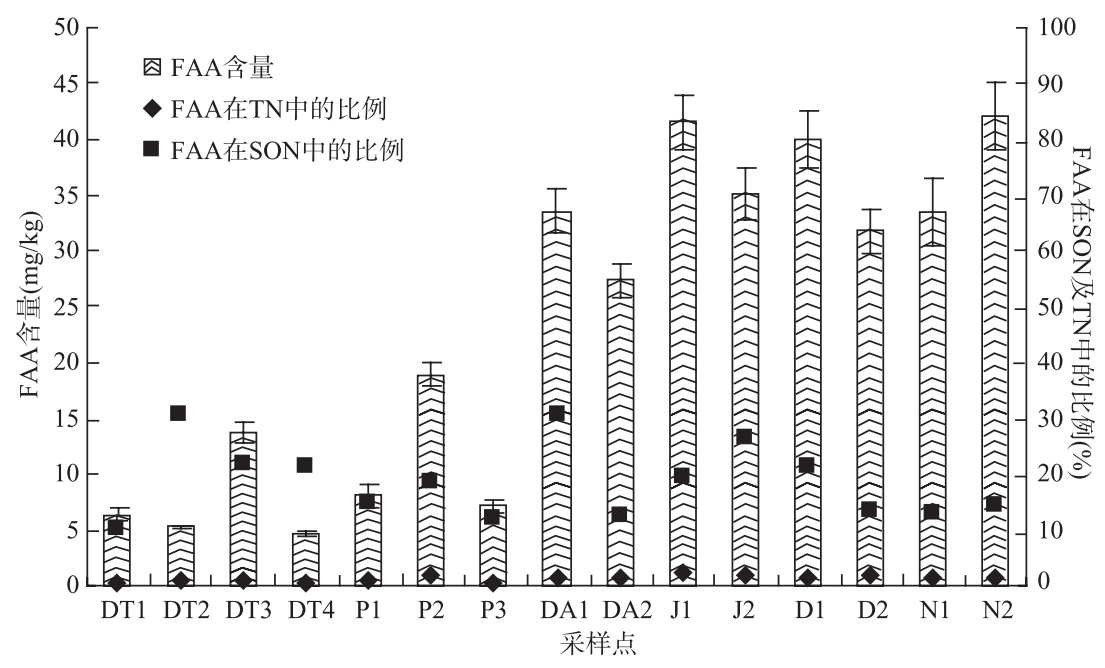

图4 沉积物中游离氨基酸含量及其在 $\mathrm{SON}$ 和TN中的比例

Fig.4 Contents of FAA and its ratio to SON and TN in lake sediments

\section{3 讨论}

\section{1 湖泊沉积物中 SON 的含量及分布}

土壤中SON的含量因提取方法的不同而异. Murphy等 ${ }^{[1]}$ 对英国 12 个农田土壤的研究发现, $\mathrm{KCl}$ 提取的 土壤 SON含量在 $20-30 \mathrm{~kg} / \mathrm{hm}^{2}$ 之间, 约占土壤可溶性总氮的 $40 \%-50 \%$. Zhong等 ${ }^{[25]}$ 用 $\mathrm{K}_{2} \mathrm{SO}_{4}$ 提取测定森林 土壤中的 SON, 得到 $\mathrm{SON}$ 占总氮的 $0.3 \%-2.2 \%$, 略高于矿质氮. 杨线等 ${ }^{[11]}$ 用 $1 \mathrm{~mol} / \mathrm{L} \mathrm{KCl}$ 提取了黄土区不同 类型土壤的SON, 发现林地枯枝落叶层中SON含量为 $248.26 \mathrm{mg} / \mathrm{kg}$, 农田黑垆土SON含量为 $24.75 \mathrm{mg} / \mathrm{kg}$, 分别占土壤总氮的 $4.36 \%$ 和 $2.54 \%$. 东北林地土壤中的 $S O N$ 含量为 $156.0-292.6 \mathrm{mg} / \mathrm{kg}^{[26]}$. 本研究用 $1 \mathrm{~mol} / \mathrm{L}$ $\mathrm{KCl}$ 提取的湖泊沉积物中 $\mathrm{SON}$ 含量为 $17.18-292.31 \mathrm{mg} / \mathrm{kg}$, 平均为 $134.45 \mathrm{mg} / \mathrm{kg}$, 占可溶性总氮 (TSN) 的 $51.86 \%$, 沉积物总氮的 $7.14 \%$, 值略高于可溶性无机氮, 污染严重的沉积物 SON含量与林地土壤研究结果 相近. 沉积物SON大小与可溶性无机氮含量大小相当, 污染严重的沉积物SON甚至大于可溶性无机氮. 与土壤相比, 湖泊沉积物 SON含量及其占总氮的比例均较高, 且可以被藻类直接利用, 也可以保持水体 的富营养化, 甚至引起水华爆发 ${ }^{[27-28]}$, 因而应重视湖泊沉积物SON的研究.

当湖泊靠近城市时, 生活污水等能导致湖泊水体溶解有机氮的显著增加, 湖泊水体中溶解有机质的 来源要考虑人类活动的影响 ${ }^{[6]}$. 所以说, 湖泊沉积物中 $\mathrm{SON}$ 的含量与人类活动的影响紧密联系. 本研究 中, SON平均含量的大小顺序为岳阳南湖 $>$ 湖南东湖 $>$ 军山湖 $>$ 大通湖 $>$ 鄱阳湖 $>$ 洞庭湖. 可见, 湖泊 沉积物中SON的含量分布除与湖泊污染程度紧密相关外, 还与人类活动干扰强度, 如污水排放、化肥养殖 
等紧密相关. 从湖泊面积考虑也是如此, 湖泊面积大小顺序为岳阳南湖 $<$ 湖南东湖 $<$ 大通湖 $<$ 军山湖 $<$ 洞庭湖<鄱阳湖, SON的高低顺序，几乎与湖泊面积一致. 军山湖例外，这是因为军山湖与大通湖相比, 渔业活动更多 ${ }^{[14]}$. 鄱阳湖高于洞庭湖的原因可能与其枯水期成河的独特自然地理景观有关. 岳阳南湖是 岳阳楼、洞庭湖的主要景区，旅游资源丰富. 由于旅游开发迅速，周边人口不断增多，娱乐活动越来越频 繁, 大量城市污水未经处理直接排人岳阳南湖 ${ }^{[29]}$, 因而其SON值是最高的. 与岳阳南湖相比, 湖南东湖 受人类干扰小一些，特别地，靠近农田的 1 号点比靠近乡村的 2 号点SON含量小. 军山湖 2 号点SON仅为 $132.10 \mathrm{mg} / \mathrm{kg}$ ，与之所处的特殊位置有关，军山湖 2 号点位于地质构造形成的湖泊支叉处，泥沙沉积少. 鄱 阳湖和洞庭湖是中国两大淡水湖泊, 湖泊面积大, SON平均含量相对较小, 因为自然湖泊的面积越大, 受 人类干扰强度越小, 沉积物中有机质的积累越少, SON越低.

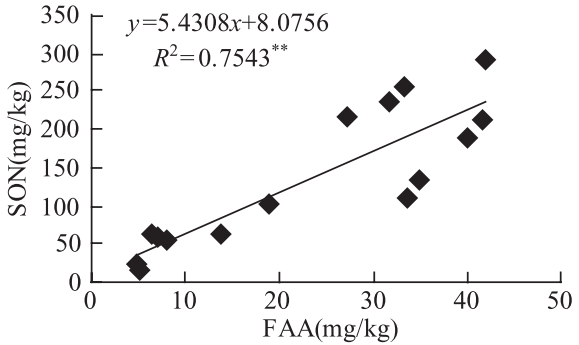

图5 游离氨基酸与 SON之间的相关关系 $(* *$ 表示相关性达 0.01 极显著水平 $)$

Fig. 5 Correlations between FAA and SON in lake sediments

\section{2 湖泊沉积物中游离氨基酸的含量及与 SON 的关系}

湖泊沉积物中FAA含量变化范围在4.69-42.04mg $/ \mathrm{kg}$ 之 间，平均为 $23.27 \mathrm{mg} / \mathrm{kg}$, 平均占 $\mathrm{SON}$ 的 $18.80 \%$, TN的 $1.24 \%$. 大亚湾沉积物中FAA的含量为 $11.48-37.66 \mathrm{mg} / \mathrm{kg}^{[12]}$, 与本 研究结果相近. 可见, 沉积物FAA含量较高. 据报道, 林地 土壤中FAA含量占SON含量的 $1.5 \%-10.6 \%{ }^{[30]}$, 农田土壤中 为 $3 \%^{[1]}$. 杨线等 ${ }^{[11]}$ 报道林地枯枝落叶层中FAA的平均含量 为 $10.95-25.47 \mathrm{mg} / \mathrm{kg}$, 占 $\mathrm{SON}$ 的 $4.46 \%-10.02 \%$. 美国加州 高山湖泊水体中FAA一般低于溶解有机氮的 $7.5 \%{ }^{[5]}$. 本研 究中FAA平均含量及其在SON中的比例高于学者们关于土 壤中的报道，这与湖泊沉积物所处的环境特征有关，可能 说明了沉积物SON含有更多的易分解组分，更容易被微生 物和植物直接利用，从而对湖泊富营养化造成影响. 同时

还研究了FAA与SON的关系(图5), 结果为显著正相关, 即SON含量越高的沉积物中易分解的组分越大.

\section{3 湖泊沉积物中 SON 含量与湖泊沉积物其它性质间的关系及其对环境的影响}

沉积物的营养水平与湖泊的污染程度有关, 污染严重的湖泊沉积物的营养水平也高. 不少学者研究 了土壤 SON与土壤氮素组分之间的关系, 发现土壤 SON与土壤氮素供应紧密相关 ${ }^{[11]}$, 可以反映土壤养分 的循环和供应状况. 本研究发现, SON与沉积物可溶性无机氮、总磷、有机质、CEC间均呈显著的正相关 关系(图6)，表明SON与湖泊氮素供应间有紧密的联系，也进一步说明了SON含量大小随沉积物污染程度
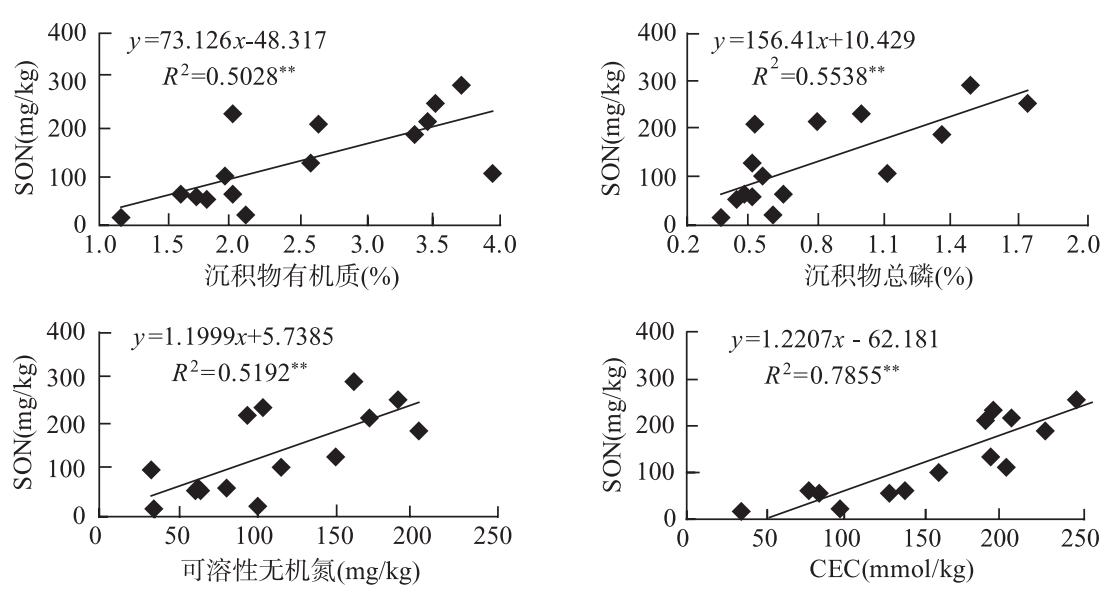

图6 SON与沉积物性质间的关系

(**表示相关性达 0.01 极显著水平)

Fig.6 Correlations between SON and different parameters in lake sediments 
增大而增大，因为沉积物总磷、有机质等均是指示湖泊污染程度的指标.

本研究发现, $1 \mathrm{~mol} / \mathrm{L} \mathrm{KCl}$ 提取的湖泊沉积物中 SON含量较大, 占沉积物总氮的比例较大, 即湖泊沉积 物中有较大的潜在氮库. 前已述及, 陆地中的SON移动性强, 容易转移到河流或湖泊中. 流失的SON通 过各种途径进人湖泊, 一部分被微生物及水生动植物直接利用, 从而减轻水体氮负荷; 一部分沉于湖底, 在沉积物中长期积累, 导致沉积物的 SON增大. 沉积物中的 $\mathrm{SON}$ 被微生物矿化而释放出 $\mathrm{NH}_{4}{ }^{+}$, 而沉积物 中的无机氮(如 $\left.\mathrm{NH}_{4}{ }^{+}\right)$会被微生物固定，同时其它形式的有机氮(如氨基酸等)也会随生物死亡而进人 SON 中 $^{[31]}$. 通常情况下, 这两种过程保持动态平衡. 但当条件改变时, 平衡被打破, 沉积物向上覆水释放SON, 或者形成易分解的其它形式氮组分, 增加水环境中的营养级别和压力 ${ }^{[32]}$, 对湖泊富营养化造成影响. 而 且, 某些可溶性有机氮能被微生物或者某些生物种类直接吸收利用 ${ }^{[33]}$, 这可能更加加剧了水体富营养化.

\section{4 结论}

(1)沉积物 $\mathrm{SON}$ 含量处于 $17.18-292.31 \mathrm{mg} / \mathrm{kg}$ 之间, 平均值为 $134.45 \mathrm{mg} / \mathrm{kg}$, 平均占沉积物总氮的 $7.14 \%$, 平均占TSN的 $51.86 \%$, 值略高于可溶性无机氮. SON含量随沉积物氮污染程度的升高而增大, 污染严重湖 泊沉积物的 $\mathrm{SON}$ 含量较轻污染沉积物高. 但表层 $10 \mathrm{~cm}$ 沉积物可能反映的是近几十年甚至是上百年的沉积 状况. 因此, 本研究中关于SON的研究结果并不能反映沉积物的污染现状, 实际情况可能更加严重.

(2)游离氨基酸含量处于 $4.69-42.04 \mathrm{mg} / \mathrm{kg}$ 间, 平均为 $23.27 \mathrm{mg} / \mathrm{kg}$, 占 $\mathrm{SON}$ 的 $18.80 \%, \mathrm{TN}$ 的 $1.24 \%$. FAA 与SON含量显著正相关, 且在沉积物中的平均含量及在SON中的比例均较土壤中高, 说明湖泊沉积物 SON有较大的易分解组分.

(3)SON与沉积物TN、TSN、FAA、有机质、CEC等显著正相关，表明SON与湖泊氮素供应间有紧密 的联系. SON对湖泊环境有深远影响, 应重视湖泊沉积物SON的研究.

\section{5 参考文献}

[1] Murphy DV, Macdonald AJ, Stockdale EA et al. Soluble organic nitrogen in agricultural soils. Soils and Fertility of Soils, 2000, 30: $374-387$.

[2] Jones DL, Willett VB. Experimental evaluation of methods to quantify dissolved organic nitrogen (DON) and dissolved organic carbon (DOC) in soil. Soil Biology \& Biochemistry, 2006, 38: 991-999.

[3] Jones DL, Shannon D, Murphy DV. Role of dissolved organic nitrogen (DON) in soil N cycling in grassland soils. Soil Biology \& Biochemistry, 2004, 36: 749-756.

[4] Jones DL, Shannon D, Fortune TJ. Plant capture of free amino acids is maximized under high soil amino acid concentrations. Soil Biology \& Biochemistry, 2005, 37: 179-181.

[5] Zehr JP, Paulsen SG, Axler RP. Dynamics of dissolved organic nitrogen in subalpine Castle Lake, California. Hydrobiologia, 1988, 157: 33-45.

[6] Li W, Wu FC, Liu CQ et al. Temporal and spatial distributions of dissolved organic carbon and nitrogen in two small lakes on the Southwestern China Plateau. Limnology, 2008, 9: 163-171.

[7] 邵孝候, Houba VJG, 胡䨠堂等. 土壤可溶性有机态氮的释放动力学研究. 南京农业大学学报(自然科学版), 1990, 13(3): 65-69.

[8] 陈文煊, 王志红. 不同形态氮对富营养化水源藻华暴发的潜在影响. 给水排水, 2008, 134(9): 22-27.

[9] Perakis SS, Hedin LO. Nitrogen loss from unpolluted South American forests mainly via dissolved organic compounds. Nature, 2002, 415: 416-419.

[10] 刘 艳, 周国逸, 刘菊秀. 陆地生态系统可溶性有机氮研究进展. 生态学杂志, 2005, 24(5): 573-577.

[11] 杨 线, 严德翼, 周建斌等. 黄土区不同类型土壤可溶性有机氮的含量及特性. 生态学报, 2007, 27(4): 1397-1403.

[12] 牟德海, 黄长江, 张春粦等. 大亚湾沉积物中氨基酸的垂直分布一一沉积物柱样 $\mathrm{W}_{0}$ 中的游离氨基酸. 分析测试学报, 2002, 21(2): 4-7.

[13] 王毛兰, 胡春华, 周文斌. 丰水期鄱阳湖氮磷含量变化及来源分析. 长江流域资源与环境, 2008, 17(1): 138-142. 
[14] 王苏民, 窦鸿身. 中国湖泊志. 北京: 科学出版社, 1998: 225 .

[15] 刘 妍, 张建明, 陈 政等. 洞庭湖水质污染现状及影响因素分析. 内陆水产, 2007, (8): 34-35.

[16] 谈毅奇, 杨品红, 桑明强等. 湖南东湖生态系统的能量结构与转换效率. 水利渔业, 2000, 20(6): 6-8.

[17] 金 宏, 向建国, 唐文熙. 大通湖渔场浮游生物及其鱼产力的调查. 内陆水产, 2005, (7): 22-35.

[18] 简永兴, 王建波, 何国庆等. 洞庭湖区三个湖泊水生植物多样性的比较研究. 水生生物学报, 2006, 30(2): 160-167.

[19] 鲍士旦. 土壤农化分析(第三版). 北京: 中国农业出版社, 2000.

[20] Ruban V, Brigault S, Demare D. An investigation of the origin and mobility of phosphorus in freshwater sediments from Bort-Les-Orgues Reservoir, France. J Environ Monit, 1999, 1: 403-407.

[21] 中国科学院南京土壤所. 土壤理化分析. 上海: 上海科技出版社, 1978: 73-92.

[22] 国家环境保护总局《水和废水监测分析方法》编委会. 水和废水监测分析方法. 北京: 中国环境科学出版社, 2002.

[23] 张＼cjkstart雷，郑丙辉，田自强. 西太湖典型河口区湖滨带表层沉积物营养评价. 环境科学与技术, 2006, 29(5): 4-6.

[24] McCarthy M, Pratum T, Hedges J. Chemical composition of dissolved organic nitrogen in the ocean. Nature, 1997, 390: $150-154$.

[25] Zhong ZK, Franz M. Soluble organic nitrogen in temperate forest soils. Soil Biology \& Biochemistry, 2003, 35: 333-338.

[26] Song LC, Hao JM, Cui XY. Soluble organic nitrogen in forest soils of northeast China. Journal of Forestry Research, 2008, 19(1): 53-57.

[27] Glibert PM. Harmful algal blooms in the Chesapeake and coastal bays of Maryland, USA: Comparison of 1997, 1998, and 1999 events. Estuaries, 2001, 24: 875-883.

[28] Tonis P, Serge YM. The role of inorganic and organic nutrients on the development of phytoplankton along a transect from the Daugava River mouth to the Open Baltic, in spring and summer. ICES Journal of Marine Science, 2003, 60: 827-835.

[29] 葛大兵, 吴小玲, 周 慧等. 岳阳南湖浮游植物与富营养化特征分析. 水资源保护, 2005, 21(2): 46-49.

[30] Yu Z, Zhang Q, Kraus TEC et al. Contribution of amino compounds to dissolved organic nitrogen in forest soils. Biogeochemistry, 2002, 61: 173-198.

[31] Chen CG, Xu ZH. On the nature and ecological functions of soil soluble organic nitrogen (SON) in forest ecosystems. $J$ Soils \& Sediments, 2006, 6(2): 63-66

[32] 吴＼cjkstart怡, 邓天龙, 廖梦霞. 天然水体沉积物中有机氮的研究进展. 广东微量元素科学, 2006, 13(11): 7-13.

[33] Lipson D, Näsholm T. The unexpected versatility of plants: organic nitrogen use and availability in terrestrial ecosystems. Oecologia, 2001, 128: 305-316. 